\title{
Optimization of drying conditions and components to reduce wall sticking during spray drying of infant formula milk
}

\author{
Yawen Lin ${ }^{1}$, Yanhong Liu ${ }^{1,2^{*}}$, Lu Wang ${ }^{1}$, Yongkang Xie ${ }^{1}$, Zhenjiang Gao ${ }^{1}$, Shaojin Wang ${ }^{3,4}$ \\ (1. College of Engineering, China Agricultural University, Beijing 100083, China; \\ 2. Jiangsu Key Laboratory of Advanced Food Manufacturing Equipment \& Technology, Wuxi 214122, Jiangsu, China; \\ 3. Department of Biological Systems Engineering, Washington State University, WA 99164-6120, USA; \\ 4. College of Mechanical and Electronic Engineering, Northwest A\&F University, Yangling 712100, Shaanxi, China)
}

\begin{abstract}
Wall sticking, which greatly reduces productivity and product quality, has been a big challenge of spray drying. Structure of drying tower and atomizer, as well as drying conditions are the main influencing factors. This research explored the possibility to reduce wall sticking by optimizing drying conditions and components to obtain higher recovery rate of powdered infant formula milk (PIFM). Response surface experimental results indicated that inlet air temperature $(T)$, feed concentration $(C)$, feeding speed $(S)$, as well as interaction term of $T C$ and quadratic terms of $C^{2}$ and $S^{2}$ had significant influences on recovery rate for determined milk formula. According to mixture experiments at optimized drying conditions, whey protein $(P)$, fat $(F)$ and lactose $(L)$ contents, as well as interaction term $F L$ had significant effects on recovery rate. Positive effects were observed for $F$ and $L$ contents on recovery rate, while negative effects were observed for $P$ and $F L$. Under the optimized drying condition of $136^{\circ} \mathrm{C}, 19.80 \%$ and $4.07 \mathrm{~mL} / \mathrm{min}$, respectively, for $T, C$ and $S$, the maximum recovery rate of $58.98 \%$ was obtained for PIFM with $P, F$ and $L$ content of $18 \%, 31 \%$ and $51 \%$, respectively. Wall sticking phenomena could be reduced by optimizing drying conditions and mildly adjusting components of infant formula milk.
\end{abstract}

Keywords: spray drying, drying condition, wall sticking, inlet temperature, feed concentration, feeding speed, powder recovery rate, infant formula milk

DOI: $10.25165 /$ j.ijabe.20181102.2788

Citation: Lin Y W, Liu Y H, Wang L, Xie Y K, Gao Z J, Wang S J. Optimization of drying conditions and components to reduce wall sticking during spray drying of infant formula milk. Int J Agric \& Biol Eng, 2018; 11(2): 214-218.

\section{Introduction}

Infant formula milk refers to milk and milk protein products with proper amount of vitamins, minerals and/or other ingredients, which are only processed by physical production method and suitable for normal infants ${ }^{[1-3]}$. In order to facilitate storage and delivery, infant formula milk is often stored in powder form. Since infants fed on infant formula milk younger than six months are often completely reliant on the nutrients in the formula milk to provide all the nutrients required for healthy growth and development, manufacturing of powdered infant formula milk is one of the most difficult, regulated and high risk branches of food manufacturing requiring great care and attention to detail at all stages, among which spray drying is one of the most important ones $^{[4]}$.

Spray drying is the most common process to obtain powdered infant formula milk, during which heat and mass transfer of the

Received date: 2016-08-14 Accepted date: 2017-01-04

Biographies: Yawen Lin, $\mathrm{PhD}$ candidate, research interests: agricultural product drying technology, Email: yezisophi@163.com; Lu Wang, Master, research interests: agricultural product drying technology, Email: wanglu01112014@163.com; Yongkang Xie, PhD candidate, research interests: agricultural product drying technology, Email: 1548057694@qq.com; Zhenjiang Gao, PhD, Professor, research interests: agricultural product drying technology, Email: zjgao@cau.edu.cn; Shaojin Wang, PhD, Professor, research interests: agricultural product processing technology, Email: shaojinwang@nwsuaf.edu.cn.

*Corresponding author: Yanhong Liu, PhD, Associate Professor, research interests: agricultural product drying technology. College of Engineering, China Agricultural University, Beijing 100083, China. Tel: +86-10-62736883, Email: liuyanhong@cau.edu.cn. atomized liquid feed or suspension occurs simultaneously in very short time ${ }^{[5,6]}$. Since drying occurs within a few seconds, the thermal damage is often considered as limited ${ }^{[7]}$. However, a big challenge of spray drying is wall sticking, which greatly reduces productivity and product quality. The major factors influencing stickiness of sugar-rich material are hygroscopicity, solubility, melting point and glass transition temperature ${ }^{[8-11]}$. With increasing hygroscopicity and solubility, or at a temperature higher than glass transition and melting point ones, stickiness of material became even larger. Therefore, some researchers suggested that the drying chamber wall temperature could be maintained lower than the glass transition temperature of the powder to reduce deposition of high sugar content powders ${ }^{[12,13]}$. Lazer et al. ${ }^{[14]}$ adopted cooling atmospheric air near the bottom cone of the spray dryer to decrease the sticking of tomato powders on the dryer walls. Zhu et al. ${ }^{[15]}$ also explored the dry mass glass transition temperature of various powders (the skim milk powder, lactose-free whey powder, and four infant milk powder samples) using a desorption isotherm in order to reduce wall sticking phenomenon. But when the temperature of the chamber wall decreased, the spray drying temperature decreased as well, which may lead to insufficient drying of particles so that they might collide with each other or with the dryer walls, finally resulting in wall sticking. Drying conditions including inlet air temperature, outlet air temperature, compressed air flow rate, drying air flow rate and atomization pressure $^{[16-19]}$, as well as structures of drying tower and atomizer ${ }^{[20,21]}$ have also been studied to reduce the degree of wall deposition and improve product functional properties. Erbay et al. ${ }^{[16]}$ optimized drying conditions of cheese powder in a pilot spray drier using response methodology and found that under optimum 
operating conditions (inlet drying temperature of $174^{\circ} \mathrm{C}$, atomization pressure of $354 \mathrm{kPa}$, and outlet drying temperature of $68^{\circ} \mathrm{C}$ ), desirability functions with minimum nonenzymatic browning index and free fat content, as well as maximum solubility index, bulk density and energy efficiency were obtained. Yu et al. ${ }^{[18]}$ investigated the effect of inlet air temperature, compressed air flow rate and drying air flow rate on recovery rate of bovine colostrum powder and found that product recovery rate decreased with increasing compressed air flow rate and drying air flow rate, while increased firstly and then decreased with drying temperature. The optimal drying parameters obtained in this experiment were inlet air temperature of $110^{\circ} \mathrm{C}$, compressed air flow rate of $300 \mathrm{~L} / \mathrm{h}$, and drying air flow rate of $0.78 \mathrm{~m}^{3} / \mathrm{min}$. $\mathrm{Jin}^{[22]}$ studied the influence of inlet air temperature, feed flow rate and total solids on the yak milk powder yield by orthogonal test during spray drying and the optimum conditions for the largest yield rate were inlet air temperature of $170^{\circ} \mathrm{C}$, feed flow rate of $10.4 \mathrm{~mL} / \mathrm{min}$ and total solids of $8.7 \mathrm{~g} / 100 \mathrm{~g}$. According to previous researches, drying conditions had significant influences on recovery rate and quality of final products. However, the optimum drying condition varied with final products, as well as structure and dimension of spray drier.

Sudhagar et al. ${ }^{[23]}$ reported that wall sticking phenomena of mango juice powders was decreased by adding $45 \%$ maltodextrin. Roustapour et al. ${ }^{[24]}$ observed addition of $10 \%$ silicon dioxide and $20 \%$ maltodextrin to lime juice helped improve the recovery rate of lime juice during spray drying, that is, composition of material also influenced recovery rate of final products. So far, very few literatures focused on the effect of the composition of infant formula milk on the recovery rate to reduce wall sticking. Samaneh et al. ${ }^{[25]}$ stated that factors such as fat, whey protein and carbohydrate contents could affect wall deposition during spray drying. Boonyai et al. ${ }^{[26]}$ pointed out that sticky components (sugar compounds), such as lactose, sucrose, fructose and glucose, had high tendency to form deposits because they are prone to stick to surfaces and other particles. However, the specific effect of these compositions, such as fat, whey protein and lactose, on recovery yield is still unavailable.

The objectives of this study were to (i) investigate the effect of drying conditions, including inlet air temperature $(T)$, feeding speed $(S)$ and feed concentration $(C)$, on the recovery rate of powdered infant formula milk; (ii) investigate the effect of main components, such as whey protein $(P)$, fat $(F)$ and lactose $(L)$ contents, under a constant drying condition on the recovery rate of the powdered infant formula milk; (iii) establish mathematical models using experimental data of response surface experiment and mixture experiment to predict recovery rate of tested powder samples at a given drying condition and main composition, respectively.

\section{Materials and methods}

\subsection{Sample preparation}

Powdered infant formula milk (PIFM) samples (Beingmate, Hangzhou, China), with protein, fat and carbohydrate content of $12.3 \%, 26.8 \%$ and $55.6 \%$, respectively, were purchased from a local supermarket in Beijing, China.

Reconstituted PIFM samples with $P, F$ and $L$ content of $10 \%-18 \%, 22 \%-31 \%$ and $51 \%-60 \%$, respectively, were prepared using whey protein, fat and lactose as listed in Table 1, based on China national food safety standards for infant formula ${ }^{[2]}$.

PIFM and reconstituted PIFM samples were dissolved into distilled water using a magnetic stirrer (SHJ-6, Hengrui Instrument
Manufacturing Co., Ltd., Changzhou, China). The solutions were then homogenized using a high pressure homogenizer (AH-100D, ATS Engineering Inc, Shanghai, China) under pressure of $16 \mathrm{MPa}$. Each sample solution was homogenized twice ${ }^{[27]}$ before being spray-dried.

Table 1 Content and type for whey protein, fat and lactose

\begin{tabular}{ccc}
\hline Component & Content $/ \%$ & Type \\
\hline Whey protein & 93 & $\begin{array}{c}\text { USA HILMAR 9410 WPI90 whey } \\
\text { protein isolate powder }\end{array}$ \\
Fat & 100 & Jonquil corn oil \\
Lactose & 99 & DAVISCO refined edible lactose \\
\hline
\end{tabular}

\subsection{Spray drying}

The homogenized PIFM and reconstituted PIFM sample solutions were dried using a laboratory spray dryer (SD-06AG, British) equipped with a spray nozzle (orifice diameter: $1.0 \mathrm{~mm}$ ) by a peristaltic pump. The maximum feeding speed of the spray dryer is about $0.6 \mathrm{~L} / \mathrm{h}$. According to the preliminary experiment results, the air quantity and the atomization pressure were set at $180 \mathrm{~m}^{3} / \mathrm{h}$ and $0.15 \mathrm{MPa}$, respectively. The schematic diagram of the spray dryer was shown in Figure 1.

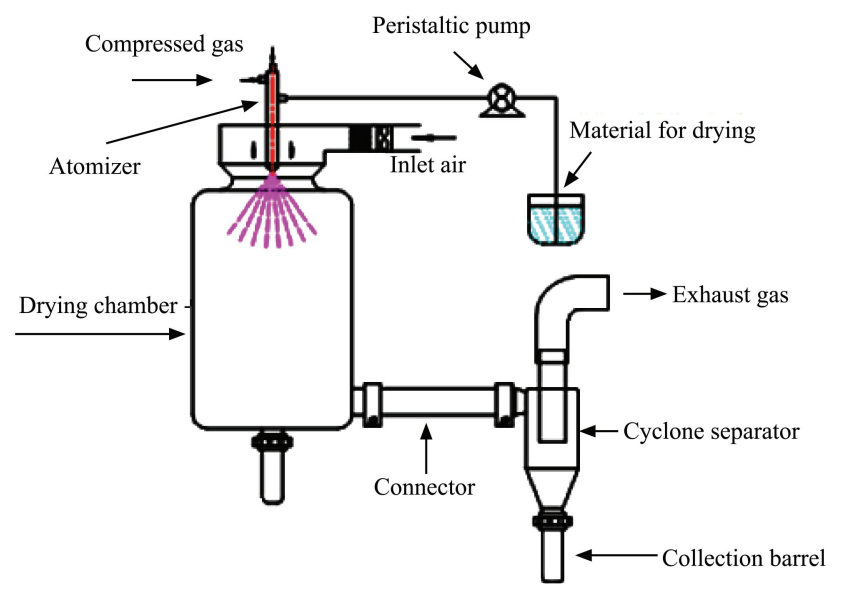

Figure 1 Schematic diagram of SD-06AG spray dryer

The homogenized PIFM sample was spray-dried using different $T, S$ and $C$. The effects of different parameters on recovery rate were then analyzed by single factor and response surface experiments. Single factor experiment was designed to analyze the effect of $T, S$ and $C$ on recovery rate, while response surface experiments was designed for analysis of interactive and quadratic effects of the three terms, as well as determination of the optimal drying condition. The detailed design of each experiment can be found in 2.3.1 and 2.3.2.

Based on the experiments 2.3.1 and 2.3.2, the optimized drying condition was obtained on which the highest recovery rate could be achieved. Under this optimized drying condition, reconstituted PIFM samples with different composition proportions were spray-dried and the influences of each component on recovery rate were analyzed. The design of composition proportion was based on mixture experiment and the detailed description can be found in 2.3.3. Each experiment was carried out in triplicate.

\subsection{Experimental design}

\subsubsection{Single factor experiment}

This experiment mainly investigated the effects of factors of $T$, $S$ and $C$ on recovery rate of PIFM. Based on our preliminary experiments, when the $T$ was lower than $130^{\circ} \mathrm{C}$, the milk cannot be dried sufficiently, thus leading to a low recovery rate, while at temperature above $160^{\circ} \mathrm{C}$, the quality of dried milk powder was 
deteriorated. Therefore, the range of $T$ was determined between $130^{\circ} \mathrm{C}$ to $160^{\circ} \mathrm{C}$. The range of $S$ was determined based on the productivity and recovery rate of the spray dryer. According to our preliminary experiments, $S$ lower than $3 \mathrm{~mL} / \mathrm{min}$ caused very low productivity, while $S$ larger than $9 \mathrm{~mL} / \mathrm{min}$ led to very low recovery rate because of insufficient drying time. Therefore, the range of $S$ was set as $3-9 \mathrm{~mL} / \mathrm{min}$. The range of $C$ was determined as $13 \%-23 \%$ according to the solubility of PIFM.

\subsubsection{Response surface experiment}

The response surface experiment was designed using Box-Behnken design module in Design Expert software (Version 8.0.6.1, Stat-Ease, Inc., Minneapolis, USA) to investigate the effect of drying conditions including $T, C$ and $S$ on recovery rate. In Box-Behnken design module, the numeric factor, block, center points per block and running times were set as 3, 1, 5 and 17, respectively. The range of $T, C$ and $S$ were based on the results of single factor experiment.

\subsubsection{Mixture experiment}

The mixture experiment was designed using optimal design module in Design Expert software (Stat-Ease, Inc., Minneapolis, USA) to study the influences of components ( $P, F$ and $L$ content) of the reconstituted PIFM samples on recovery rate. In optimal design module, the numeric factor, block, center points per block and running times were set as 3, 1, 5 and 16, respectively. The range of $P, F$ and $L$ content were set as $10 \%-18 \%, 22 \%-31 \%$ and $51 \%-60 \%$, and the total sum of the three factors was set as $100 \%$.

\subsection{Data analysis}

The obtained recovery rate data of PIFM during response experiment and reconstituted PIFM samples during mixture experiment were analyzed using Design-expert 8.0.6.1 to develop mathematical models to describe the relationship between recovery rate and investigated factors. Analysis of variance (ANOVA) was used to evaluate the significance of experimental variables.

\section{Results and discussion}

\subsection{Effects of inlet air temperature on recovery rate}

Figure 2 shows the effect of $T$ on recovery rate of PIFM under constant $S(5 \mathrm{~mL} / \mathrm{min})$ and $C(18 \%)$. There was an optimal $T$ of around $140^{\circ} \mathrm{C}$ at which the milk was just dried enough upon getting to the collection barrel, and thus the maximum recovery rate was obtained. Similar phenomenon was observed in yak milk powders $^{[22]}$ and mushroom powders ${ }^{[28]}$. With the decrease of $T$ below $140^{\circ} \mathrm{C}$, the milk solution could not be dried enough in the same time, which meant the final product was under-dried upon entering the collection barrel, leading to wall sticking corresponding to less recovery rate. While with increasing $T$ above $140^{\circ} \mathrm{C}$, the final product could be dried enough before entering the collection barrel, that is, it might stay at collector or even drying chamber, leading to less recovery rate. With the decrease of $S$ or increase of $C$, the final product could be dried in shorter time, which meant a lower $T$ could be applied for optimal recovery rate. Considering the fact that lower temperature as $130^{\circ} \mathrm{C}$ was beneficial for better product quality, while high production efficiency can be achieved at higher temperature as $160^{\circ} \mathrm{C}$, and the recovery rates at both temperatures were relatively high, the range of $T$ in response surface experiment was still set as $130^{\circ} \mathrm{C}-160^{\circ} \mathrm{C}$

\subsection{Effects of feeding speed on recovery rate}

Figure 3 shows the effect of $S$ on recovery rate of PIFM under constant $T\left(140^{\circ} \mathrm{C}\right)$ and $C(18 \%)$. An optimal $S$ of around $5 \mathrm{~mL} / \mathrm{min}$ was observed at which the milk was just dried enough upon getting to the collection barrel, and thus the maximum recovery rate was obtained. Similar findings were observed in mushroom powders ${ }^{[28]}$ and bitter gourd powders ${ }^{[29]}$. With the decrease of $S$ below $5 \mathrm{~mL} / \mathrm{min}$, less solution was sprayed into drying chamber, so that the final product was dried enough and settled before entering the collection barrel, leading to less recovery rate in the collection barrel. While with increasing $S$ above $5 \mathrm{~mL} / \mathrm{min}$, more solution was sprayed into drying chamber, so that the final product was not dried enough upon entering the collection barrel, leading to wall sticking in the collection barrel corresponding to less recovery rate. With the increase of $T$ or $C$, milk solution could be dried in shorter time, accordingly, a higher $S$ could be applied for optimal recovery rate meanwhile obtaining higher production efficiency. Therefore, $9 \mathrm{~mL} / \mathrm{min}$ was still adopted in response surface experiment even though the recovery rate was pretty low at given drying conditions.

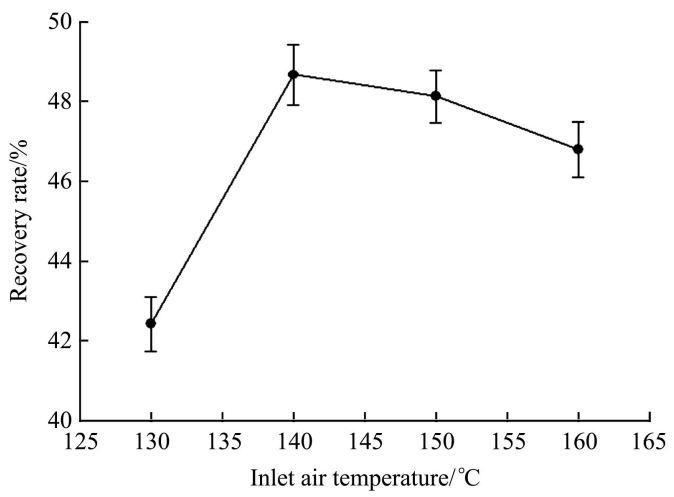

Figure 2 Recovery rate of PIFM under different inlet air temperature

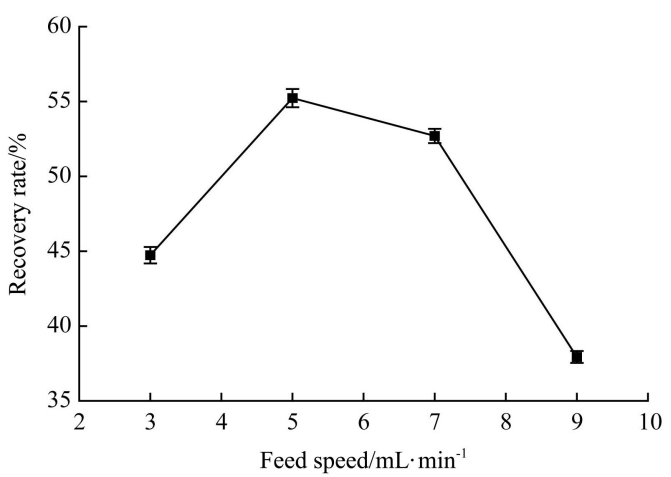

Figure 3 Recovery rate of PIFM under different feeding speeds

\subsection{Effects of feed concentration on recovery rate}

Figure 4 shows the effect of $C$ on recovery rate of PIFM under constant $T\left(140^{\circ} \mathrm{C}\right)$ and $S(5 \mathrm{~mL} / \mathrm{min})$. There was an optimal $C$ of around $17 \%$ at which the milk was just dried enough upon getting to the collection barrel, and thus the maximum recovery rate was obtained. $\mathrm{Lu}$ et al. ${ }^{[28]}$ also found similar phenomenon in her research of burdock powder. With the decrease of $C$ below $17 \%$, due to the higher moisture content in milk solution, the final product could not be dried enough upon getting into the collection barrel, leading to wall sticking inside the collection barrel, corresponding to less recovery rate. While with increasing $C$ above $17 \%$, due to the smaller moisture content in milk solution, the final product could be dried enough and deposited before getting into the collection barrel, leading to less recovery rate. With decreasing $T$ or increasing $S$, milk solution has to be dried in longer time, accordingly, a lower $C$ could be applied for optimal recovery rate, vice versa. Considering the fact that the recovery 
rate difference at given $C$ in this research was not high, the range of $C$ in the response surface experiment was still set as 13\%-23\%.

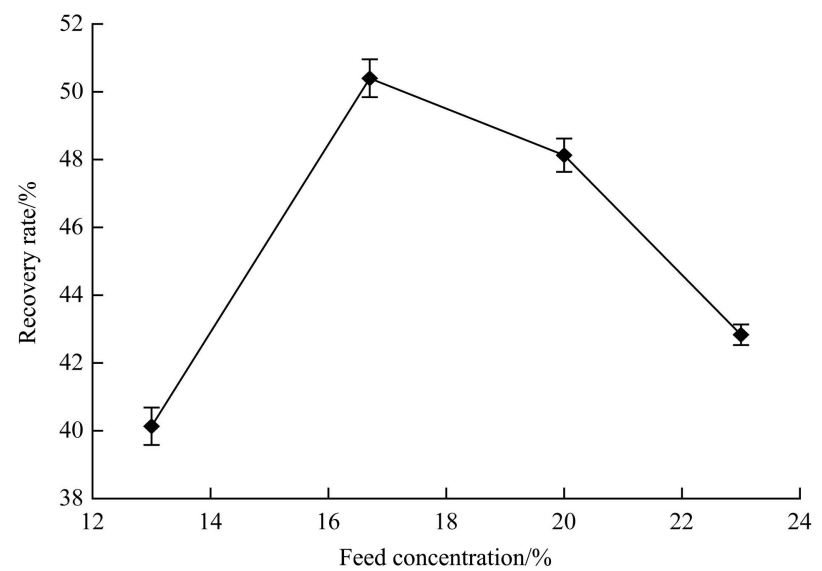

Figure 4 Recovery rate of PIFM under different feed concentration

\subsection{Effects of drying condition on recovery rate}

The experimental conditions and the corresponding recovery rates were shown in Table 2 and the analysis of variance for Table 2 was shown in Table 3. Table 3 showed that the model 'Prob $>F$ ' value was less than 0.05 which implied the model was significant, similarly, $T, C, S, T C, C^{2}, S^{2}$ were significant model terms while the effects of $T S, C S$ or $T^{2}$ on the recovery rate was not significant. These insignificant terms were then deleted from the quadratic model to gain a modified quadratic model, which can describe the relationship between recovery rate and influencing factors more simply. The obtained modified quadratic model was shown in Equation (1) where $R_{1}$ represented recovery rate in response surface experiment.

$$
\begin{aligned}
R_{1}=- & 0.434 T+2.892 C+2.404 S+0.0134 T C-0.129 C^{2}- \\
& 0.231 S^{2}+65.203
\end{aligned}
$$

Positive effects were observed for factors of $C, S$ and $T C$ on recovery rate, while negative effects for the other terms. On the optimized drying condition for our experimental facilities of $136^{\circ} \mathrm{C}$, $19.80 \%$ and $4.07 \mathrm{~mL} / \mathrm{min}$, respectively, for $T, C$ and $S$, the maximum recovery rate of $55.67 \%$ was obtained.

Table 2 Box-Behnken design of the response surface experiment

\begin{tabular}{ccccc}
\hline No. & $T /{ }^{\circ} \mathrm{C}$ & $C / \%$ & $S / \mathrm{mL} \cdot \mathrm{min}^{-1}$ & Recovery rate $\%$ \\
\hline 1 & 130 & 13 & 6 & 53.88 \\
2 & 160 & 13 & 6 & 44.84 \\
3 & 130 & 23 & 6 & 54.47 \\
4 & 160 & 23 & 6 & 49.51 \\
5 & 130 & 18 & 3 & 57.19 \\
6 & 160 & 18 & 3 & 51.37 \\
7 & 130 & 18 & 9 & 52.76 \\
8 & 160 & 18 & 9 & 47.95 \\
9 & 145 & 13 & 3 & 49.73 \\
10 & 145 & 23 & 3 & 50.86 \\
11 & 145 & 13 & 9 & 47.28 \\
12 & 145 & 23 & 9 & 50.44 \\
13 & 145 & 18 & 6 & 54.77 \\
14 & 145 & 18 & 6 & 54.77 \\
15 & 145 & 18 & 6 & 54.77 \\
16 & 145 & 18 & 6 & 54.77 \\
17 & 145 & 18 & 6 & 54.77 \\
\hline
\end{tabular}

Table 3 Analysis of variance for response surface experiment quadratic model

\begin{tabular}{cccccc}
\hline Source & Sum of squares & $\mathrm{d} f$ & Mean square & $F$ value & $p$-value Prob $>F$ \\
\hline Model & 159.1433 & 9.0000 & 17.6826 & 25.5538 & 0.0002 \\
$T$ & 63.9999 & 1.0000 & 63.9999 & 92.4886 & $<0.0001$ \\
$C$ & 11.3798 & 1.0000 & 11.3798 & 16.4453 & 0.0048 \\
$S$ & 9.5485 & 1.0000 & 9.5485 & 13.7988 & 0.0075 \\
$T C$ & 4.1751 & 1.0000 & 4.1751 & 6.0336 & 0.0437 \\
$T S$ & 0.2464 & 1.0000 & 0.2464 & 0.3561 & 0.5695 \\
$C S$ & 1.0318 & 1.0000 & 1.0318 & 1.4912 & 0.2616 \\
$T^{2}$ & 3.6098 & 1.0000 & 3.6098 & 5.2167 & 0.0563 \\
$C^{2}$ & 42.1971 & 1.0000 & 42.1971 & 60.9806 & 0.0001 \\
$S^{2}$ & 17.3012 & 1.0000 & 17.3012 & 25.0026 & 0.0016 \\
\hline Note: values of 'Prob $>F$ ' less than 0.05 indicated model terms are significant.
\end{tabular}

\subsection{Effects of component on recovery rate}

The arrangement of mixture experiments and the corresponding recovery rates were shown in Table 4 and the analysis of variance of optimal design of the mixture experiment was shown in Table 5. Table 5 showed that the model 'Prob $>F$ ' value was less than 0.05 , which suggesting that the model was significant, likewise, $P, F, L$ and $F L$ were significant model terms, while the effects of the other terms on the recovery rate were not significant. Terms of $P L$ and $P F$ were then deleted from the quadratic model to gain a modified quadratic model to describe the relationship between recovery rate and influencing factors more accurately. The obtained modified quadratic model was showed in Equation (2) where $R_{2}$ represented recovery rate in mixture experiment.

Table 4 Optimal design of the mixture experiment

\begin{tabular}{ccccc}
\hline No. & $P / \%$ & $F / \%$ & $L / \%$ & Recovery rate/\% \\
\hline 1 & 13.51 & 26.49 & 60.00 & 50.55 \\
2 & 13.51 & 26.49 & 60.00 & 50.54 \\
3 & 18.00 & 22.00 & 60.00 & 57.32 \\
4 & 18.00 & 22.00 & 60.00 & 57.31 \\
5 & 11.97 & 28.86 & 59.17 & 48.68 \\
6 & 10.00 & 31.00 & 59.00 & 48.04 \\
7 & 16.44 & 24.92 & 58.64 & 49.34 \\
8 & 11.95 & 31.00 & 57.05 & 51.97 \\
9 & 15.04 & 27.94 & 57.01 & 51.28 \\
10 & 18.00 & 26.48 & 55.52 & 54.01 \\
11 & 18.00 & 26.48 & 55.52 & 54.01 \\
12 & 13.98 & 31.00 & 55.02 & 55.18 \\
13 & 13.98 & 31.00 & 55.02 & 55.17 \\
14 & 17.34 & 29.06 & 53.59 & 53.23 \\
15 & 18.00 & 31.00 & 51.00 & 58.07 \\
16 & 18.00 & 31.00 & 51.00 & 58.07 \\
\hline & & & & \\
\hline
\end{tabular}

Table 5 Analysis of variance for mixture experiment quadratic model

\begin{tabular}{cccccc}
\hline Source & Sum of squares & $\mathrm{d} f$ & Mean square & $F$ value & $p$-value Prob $>F$ \\
\hline Model & 154.03 & 5 & 30.81 & 17.64 & 0.0001 \\
Linear mixture & 103.36 & 2 & 51.68 & 29.60 & $<0.0001$ \\
$P F$ & 5.32 & 1 & 5.32 & 3.05 & 0.1116 \\
$P L$ & 2.37 & 1 & 2.37 & 1.36 & 0.2708 \\
$F L$ & 34.40 & 1 & 34.4 & 19.7 & 0.0013 \\
\hline
\end{tabular}

Note: values of 'Prob $>F$ ' less than 0.05 indicated model terms are significant. 


$$
R_{2}=-2.766 P+10.305 F+3.157 L-0.235 F L
$$

Positive effects were observed for $F$ and $L$ contents on recovery rate, while negative effects for $P$ and $F L$. When the content of $P, F$ and $L$ was $18 \%, 31 \%$ and $51 \%$, respectively, the maximum recovery rate of $58.98 \%$ was obtained.

\section{Conclusions}

Wall sticking phenomenon during spray drying process can be reduced by optimizing drying condition and sample composition. Recovery rate of PIFM could be improved by raising feed concentration $(C)$, feeding speed $(S)$, interaction term $T C$ and fat $(F)$, lactose $(L)$ contents, or reducing the inlet air temperature $(T)$, with quadratic terms $C^{2}, S^{2}$ and whey protein $(P)$, with interaction term $F L$. The method to improve recovery rate by optimizing drying condition and mildly adjusting components proportion can also be applied in larger scale spray drying of infant formula milk.

The orifice diameter of the nozzle used in the laboratory spray dryer was $1.0 \mathrm{~mm}$ and the particle size of the dried powder was just about $10 \mu \mathrm{m}$, which was smaller than commercial PIFM (>100 $\mu \mathrm{m})$. As a result, final products might be easier to be taken by wind into the exhaust duct and thus to reduce the recovery rate. In the future study, it can be considered using nozzles with larger orifice diameters to further investigate the effect of dry product particle size on recovery rate.

\section{Acknowledgements}

The authors acknowledge that this work was financially supported by the National Natural Science Foundation of China (31301563) and Jiangsu Key Laboratory of Advanced Food Manufacturing Equipment \& Technology (FM-2014).

\section{[References]}

[1] Jan M S. Dairy products and health: Focus on their constituents or on the matrix? International Dairy Journal, 2008; 18: 425-435.

[2] National food safety standards infant formula. GB 10765-2010. Beijing, 2010.

[3] Murphy S C, Martin N H, Barbano D M, Wiedmann M. Influence of raw milk quality on processed dairy products: How do raw milk quality test results relate to product quality and yield? Journal of Dairy Science, 2016; 99(12): 10128-10149.

[4] Ravula S R, Ramachandraa C T, Sharanagouda H, Udaykumar N, Jagjiwan $\mathrm{R}$, Mouneshwari K. Influence of processing conditions on functional andreconstitution properties of milk powder made from Osmanabadi goat milk by spray drying. Small Ruminant Research, 2014; 119(1-3): 130-137.

[5] Hanus M J, Langrish, T A G. Review: Resuspension of wall deposits in spray dryers. Journal of Zhejiang University Science A, 2007; 8(11): $1762-1774$

[6] Moejes S N, van Boxtel A J B. Energy saving potential of emerging technologies in milk powder production. Trends in Food Science \& Technology, 2017; 60: 31-42.

[7] Malafronte L, Ahrne L, Schuster E, Innings F, Rasmuson A. Exploring drying kinetics and morphology of commercial dairy powders. Journal of Food Engineering, 2015; 158: 58-65.

[8] Fujimori M, Kadota K, Kato K, Seto Y, Onoue S, Sato H, et al. Low hygroscopic spray-dried powders with trans-glycosylated food additives enhance the solubility and oral bioavailability of ipriflavone. Food Chemistry, 2016; 190: 1050-1055.
[9] Jayasundera M, Adhikari B, Howes T, Aldred P. Surface protein coverage and its implications on spray-drying of model sugar-rich foods: Solubility, powder production and characterisation. Food Chemistry, 2011; 128(4): 1003-1016.

[10] Rannou C, Queveau D, Beaumal V, David-Briand E, le Borgne C, Meynier A, et al. Effect of spray-drying and storage conditions on the physical and functional properties of standard and $n-3$ enriched egg yolk powders. Journal of Food Engineering, 2015; 154: 58-68.

[11] Bhandari B R, Datta N, Howes T. Problems associated with spray drying of sugar-rich foods. Drying Technology, 1997; 15(2): 671-684.

[12] Hennigs C, Kockel T K, Langrish T A G. New measurements of the sticky behavior of skim milk powder. Drying Technology, 2001; 19: 471-484.

[13] Samaneh K, Wan R W D, Nourouzi M M, Farideh N, Mostafa G. Spray drying: An overview on wall deposition, process and modeling. Journal of Food Engineering, 2015; 146: 152-162.

[14] Lazer M E, Brown A H, Smith G S, Wang F F, Lindquist F E. Experimental production of tomato powder by spray drying. Food Technology, 1956; 129-134.

[15] Zhu P, Mejean S, Blanchard E, Jeantet R, Schuck P. Prediction of dry mass glass transition temperature and the spray drying behaviour of a concentrate using a desorption method. Journal of Food Engineering, 2011; 105: 460-467.

[16] Erbay Z, Koca N, Kaymak-Ertekin F, Ucuncu M. Optimization of spray drying process in cheese powder production. Food and Bioproducts Processing, 2015; 93:156-165.

[17] Maury M, Murphy K, Kumar S, Shi L, Lee G. Effects of process variables on the powder yield of spray-dried trehalose on a laboratory spray-dryer. Eur J Pharm Biopharm, 2005; 59(3): 565-573.

[18] Yu H N, Ardil A, Long W Y, Li Y F. Low-temperature spray drying performance of laboratory spray dryer for bovine colostrum powder. Transactions of the CSAE, 2010; 26(10): 361-366. (in Chinese)

[19] Anjali V, Satya V S. Spray drying of fruit and vegetable juices-A review. Food Science and Nutrition, 2015; 55: 701-719.

[20] Francia V, Martín L, Bayly A E, Simmons M J H. Particle aggregation in large counter-current spray drying towers: Nozzle configuration, vortex momentum and temperature. Procedia Engineering, 2015; 102: 668-675.

[21] Wawrzyniak P, Podyma M, Zbicinski I, Bartczak Z, Rabaeva J. Modeling of air flow in an industrial countercurrent spray-drying tower. Drying Technology, 2012; 30(2): 217-224.

[22] Jin Y C. Optimization of spray drying technology in proceing yak milk powder. Chinese Qinghai Journal of Animal and Veterinary Sciences, 2014; 44(6): 16-17. (in Chinese)

[23] Sudhagar M, Jaya S, Das H. Sticky issues on spray drying of fruit juices. The Society for Engineering in Agricultural, Food and Biological System. An ASAE Meeting Presentation. September 27-28, 2002. Paper No: MBSK 02-201.

[24] Roustapour O R, Hosseinalipour M, Ghobadian B. An experimental investigation of lime juice drying in a pilot plant spray dryer. Drying Technology, 2006; 24(2): 181-188.

[25] Samaneh K, Wan R W D, Nourouzi M M, Farideh N, Mostafa G. Spray drying: An overview on wall deposition, process and modeling. Journal of Food Engineering, 2015; 146: 152-162.

[26] Boonyai P, Bhandari B, Howes T. Stickiness measurement techniques for food powders: A review. Powder Technology, 2004; 145(1): 34-46.

[27] Sfakianakis P, Topakas E, Tzia C. Comparative study on high-intensity ultrasound and pressure milk homogenization: Effect on the kinetics of yogurt fermentation process. Food and Bioprocess Technology, 2014; 8(3): 548-557.

[28] Lu F, Li B, Cheng Y D, Liu X L. Optimization of spray drying technology in mushroom powder. Edible Fungi, 2012; 34(6): 57-58.

[29] Zhang M, He J P, Zhao Y H. Study on technology for making compound bitter gourd powder by spray drying. The Beverage Industry, 2011; 14(6) 34-37. 